\title{
ANÁLISE DE FALHA DO CONVERTEDOR 2*
}

Flávio Altoé Franco ${ }^{1}$ Sérgio Lopes Mattedi

\section{Resumo}

Foi identificada uma trinca no convertedor 2 da ArcelorMittal Tubarão em junho de 2013 durante início de carregamento de gusa, esta se localizava na solda entre o cone inferior e o flange do fundo. A análise abrangeu a avaliação dos danos no vaso, à análise da fratura, análise de material, onde foi verificado que a trinca não foi decorrente de trinca preexistente, nem de degradação do material ou imperfeição de solda. Foi construído um modelo 3D do convertedor considerando-se todos os detalhamentos pertinentes à uma análise termo estrutural. Foram analisadas as seguintes situações: Refratamento conforme projeto do fornecedor - junta de papelão; Projeto de refratamento incluindo influência da junta de dilatação natural $0,2 \mathrm{~mm}$ existente no refratário; Carregamento térmico; e situação corrente do projeto considerando proteção de soleira. De acordo com os resultados, verificou-se que a causa da falha do convertedor esta relacionada a esforços oriundos da expansão térmica do refratário.

Palavras-chave: Convertedor 2; Trinca; Análise de material; Análise termo estrutural.

\section{Abstract}

\section{CONVERTER 2 FAILURE ANALYSIS}

A crack has been identified in ArcelorMittal Tubarão converter 2 in June 2013 during the beginning of pig iron loading. This crack was located in the weld between the lower cone and the bottom ring. The analysis covered the vessel damage evaluation, the fracture analysis and the material analysis, which concluded that the crack was not caused by preexisting crack or degradation of the material or weld imperfection. So It was built a 3D model of the converter, and all relevant detailing to a structural term analysis were included. The following situations were analyzed: Supplier Refractory Project using paper spacer; Supplier Refractory Project including the influence of existing natural refractory board of $0.2 \mathrm{~mm}$; Thermal load; and current situation considering sole protection. According to our analysis, the cause of converter failure is related to stress originated from refractory thermal expansion.

Keywords: Converter 2; crack; Material Analysis; Term structural Analysis.

1 Engenheiro Mecânico, Especialista de Engenharia Mecânica, Engenharia de Manutenção Mecânica, ArcelorMittal Tubarão, Serra, ES, Brasil.

2 Mestre em Engenharia Mecânica, Especialista de Engenharia Mecânica, Engenharia de Manutenção Mecânica, ArcelorMittal Tubarão, Serra, ES, Brasil. 


\section{INTRODUÇÃO}

Foi identificada no convertedor 2 em 27/06/2013 durante início de carregamento de gusa, uma trinca na solda de união do cone inferior com o anel do fundo. $\mathrm{O}$ objetivo deste trabalho foi identificar a causa básica da fratura ocorrida no convertedor.

\section{MATERIAIS E MÉTODOS}

\subsection{Trinca na Carcaça}

Foi identificada no convertedor 2 em 27/06/2013 durante início de carregamento de gusa, uma trinca na solda de união do cone inferior com o anel do fundo. A trinca propagou se paralela a solda do fundo, com extensão de $5.680 \mathrm{~mm}$ no perímetro do vaso o que representa $34 \%$ do perímetro total. A abertura da trinca variou de 80 a $120 \mathrm{~mm}$, ver Figuras 1 e 2.

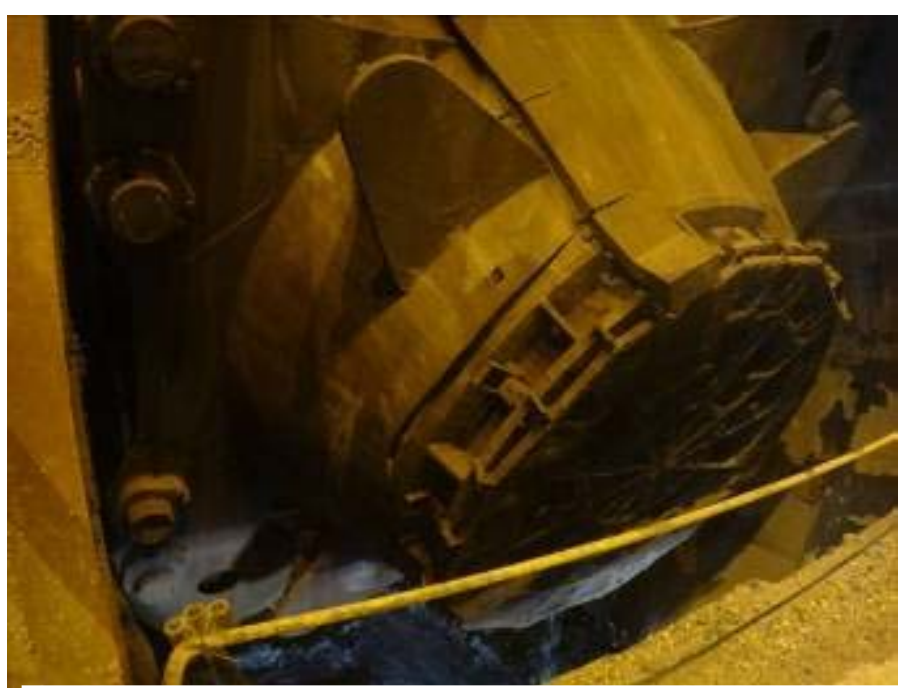

Figura 1. Vista externa da região trincada.

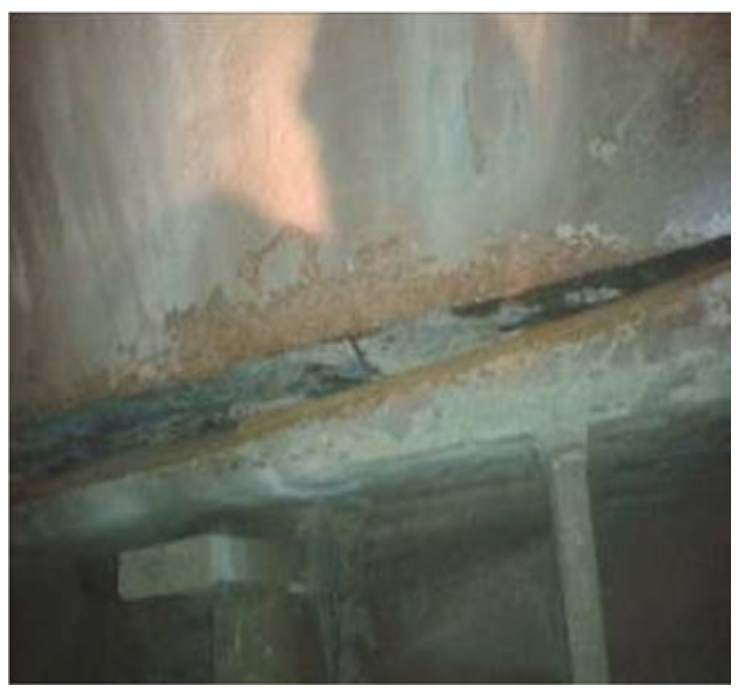

Figura 2. Abertura da trinca.

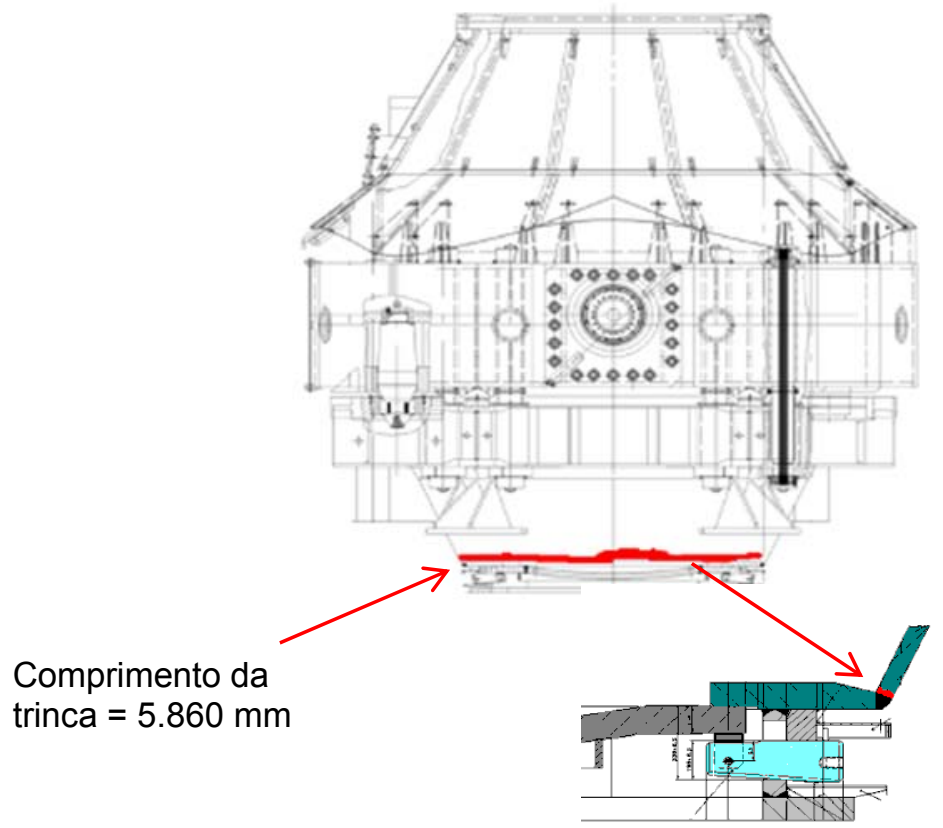

Trinca ocorreu na ZTA da solda com o cone inferior

Figura 3. Localização da trinca no vaso. 
A trinca teve origem na ZTA (zona termicamente afetada) da solda de união entre o costado e o fundo e propagou paralelamente a solda na região do costado (figura 3). O convertedor 2 esteve fora de operação por 80 horas, recebeu aquecimento conforme padrão e na sequência recebeu início da carga de gusa quando foi identificada a trinca.

\subsection{Região de Fratura}

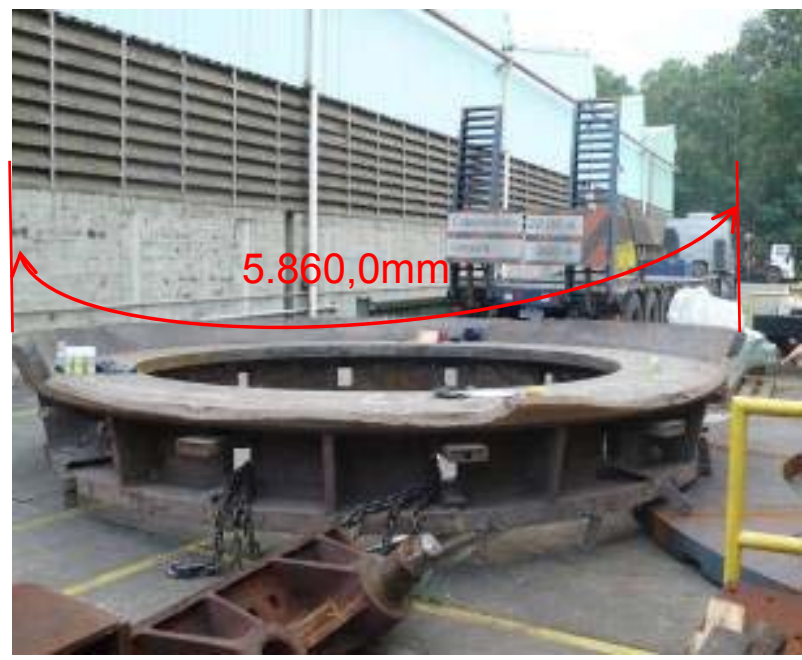

Figura 4. Vista da região de trinca.

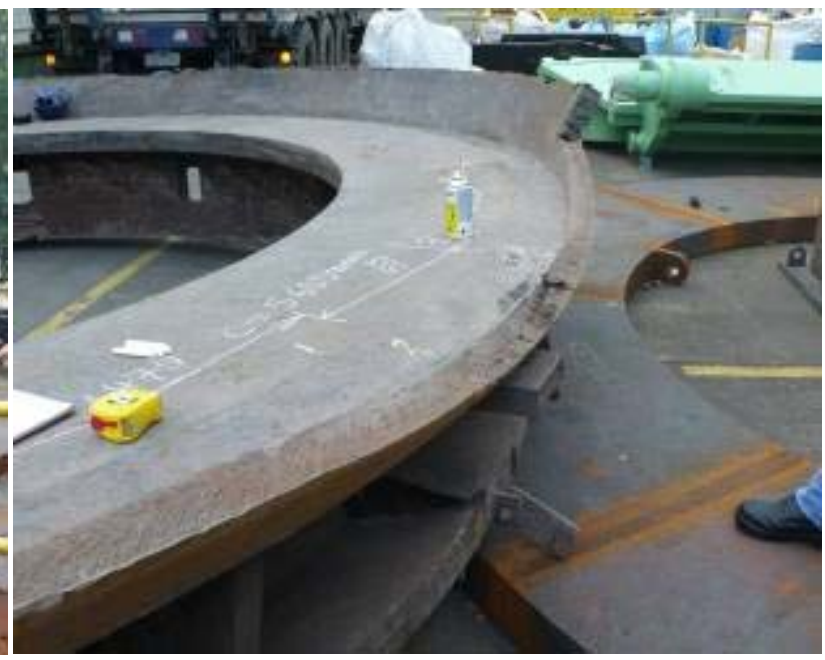

Figura 5. Vista de parte da trinca.

Avaliando a superfície de fratura, ver figuras 4 e 5 , observa se os 4 locais de iniciação da fratura, localizados na ZTA (zona termicamente afetada da solda) no lado do cone inferior. Os locais de iniciação são todos a partir da superfície interna da carcaça propagando-se para a superfície externa. Nos pontos de iniciação não se observa região de fadiga, a fratura iniciou-se e propagou-se de forma instantânea, ver figuras 6 a 8 .

\subsubsection{Superfície de Fratura - locais de origem}

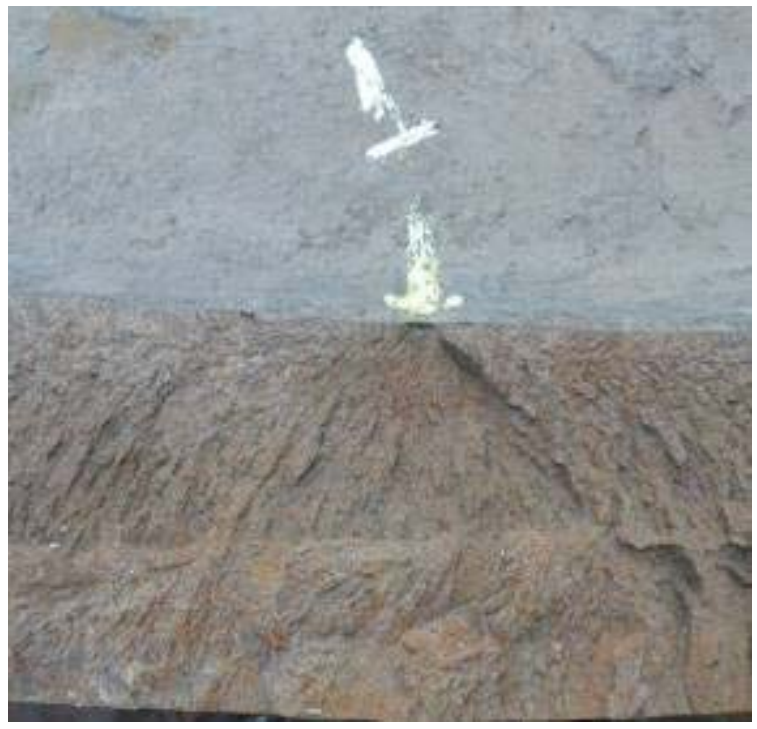

Figura 6. Origem 1 da fratura.

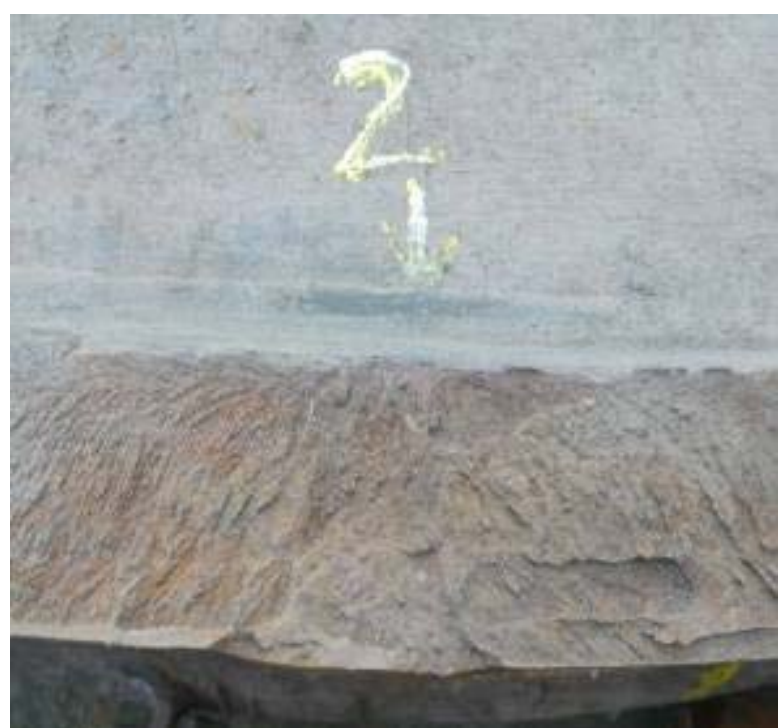

Figura 7. Origem 2 da fratura. 


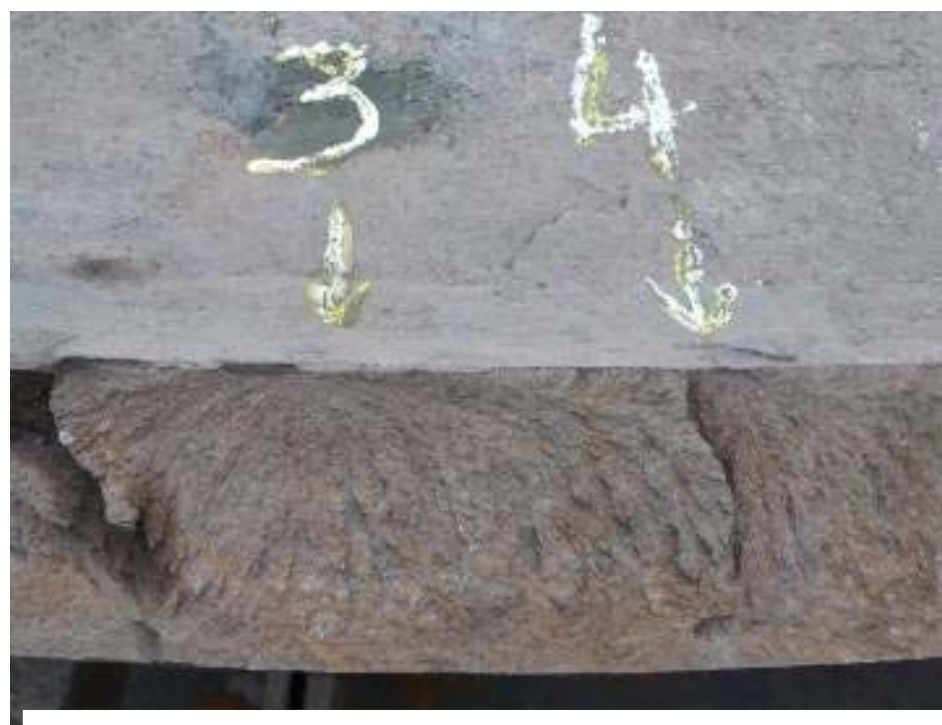

Figura 8. Origem 3 e 4 da fratura.

\subsection{Deformação da Carcaça}

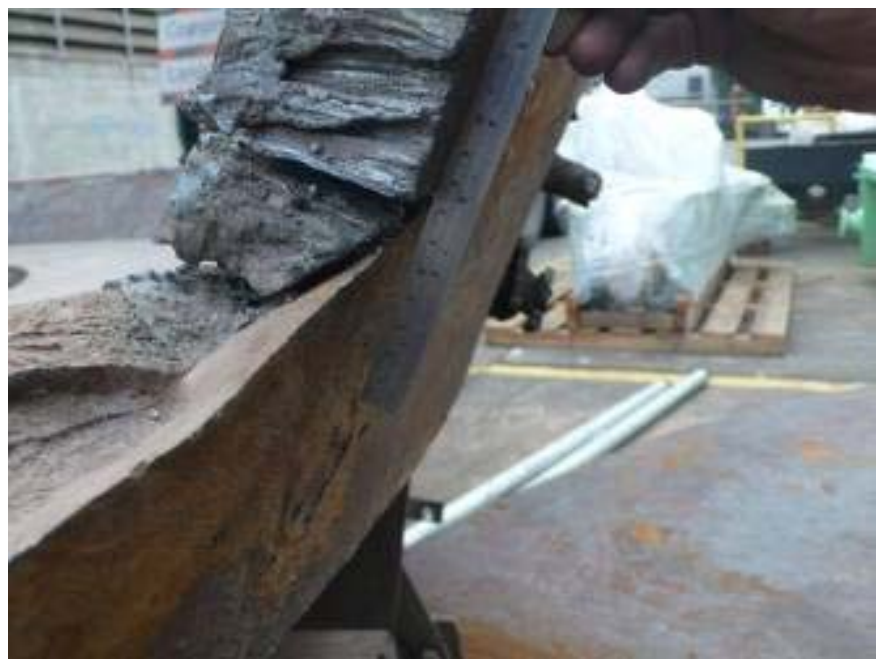

Figura 9. Deformação do cone inferior, lado externo.

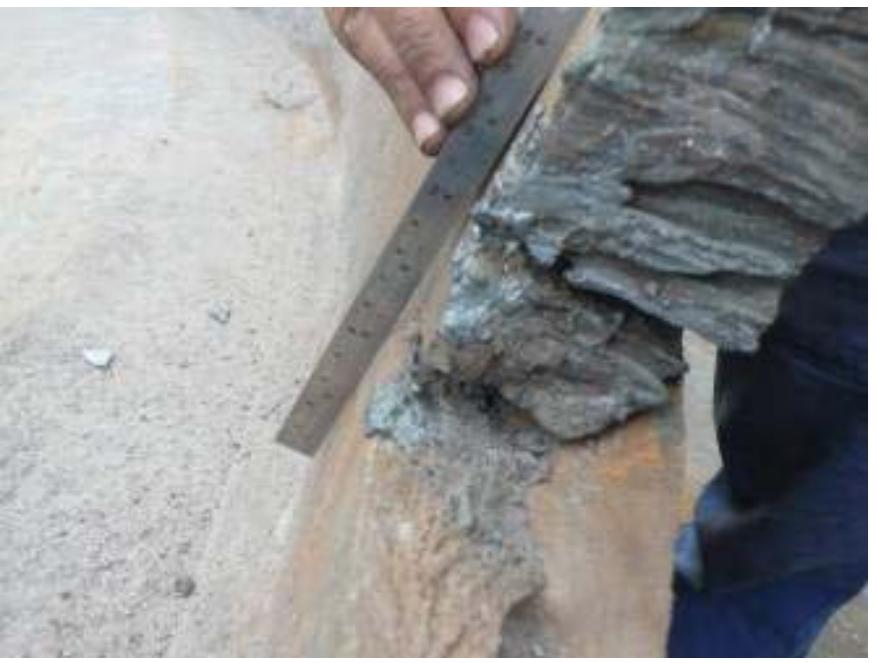

Figura 10. Deformação do cone inferior, lado interno.

Verficando o cone inferior do costado na região da fratura observa-se deformação deste com relação ao anel do fundo, ver figuras 9 e 10.

\subsection{Inspeção na Estrutura do Fundo}

$\mathrm{Na}$ inspeção visual na estrutura do fundo do convertedor foram identificadas trincas nas soldas das nervuras e dos suportes de chavetas em todo o perímetro, ver figuras 11 a 13 . Essas regiões já foram recuperadas em campanhas anteriores do convertedor. 


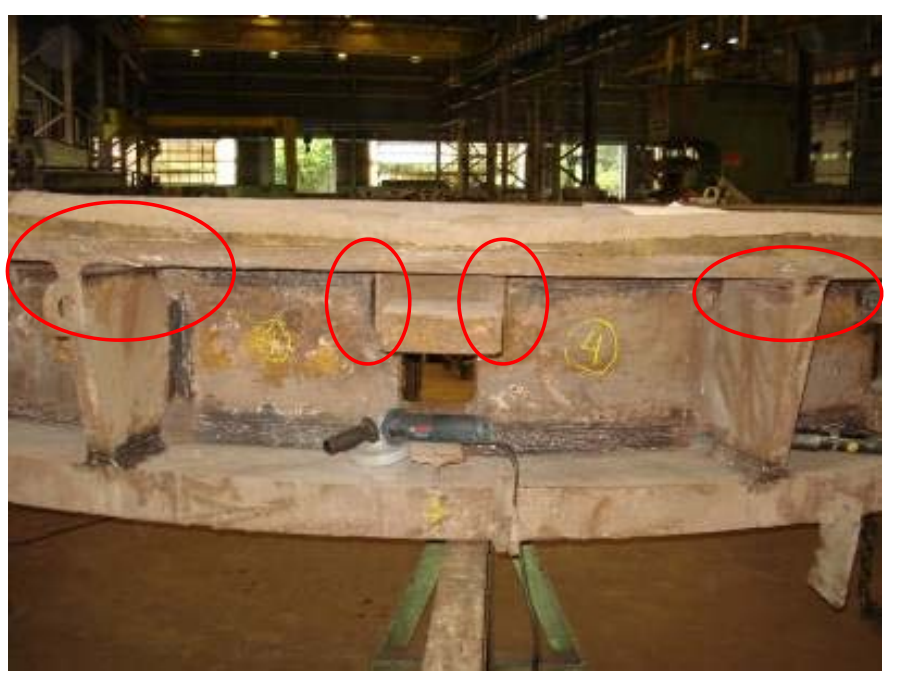

Figura 11. Foram encontradas trincas nas soldas indicadas.

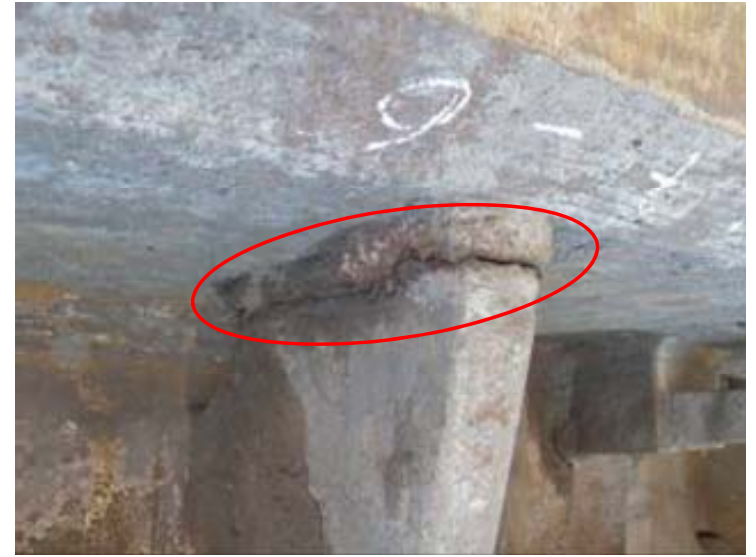

Figura 12. Trinca de $75 \mathrm{~mm}$ na nervura 5-6.

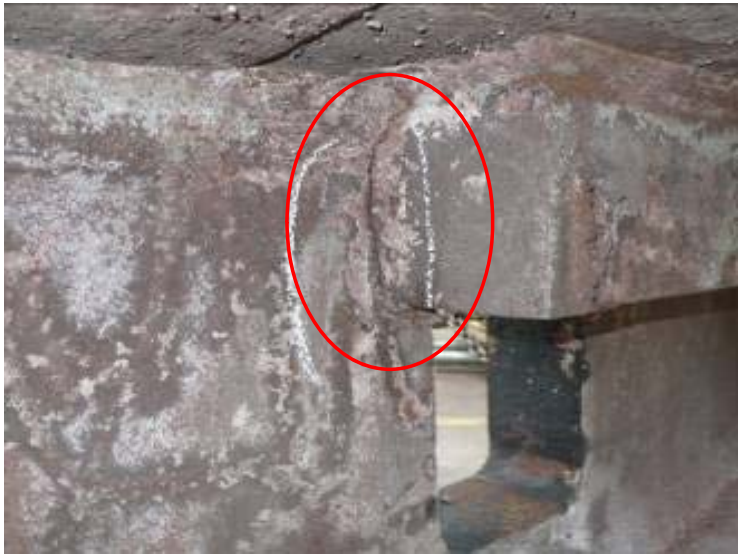

Figura 13. Trinca na solda do suporte da chaveta.

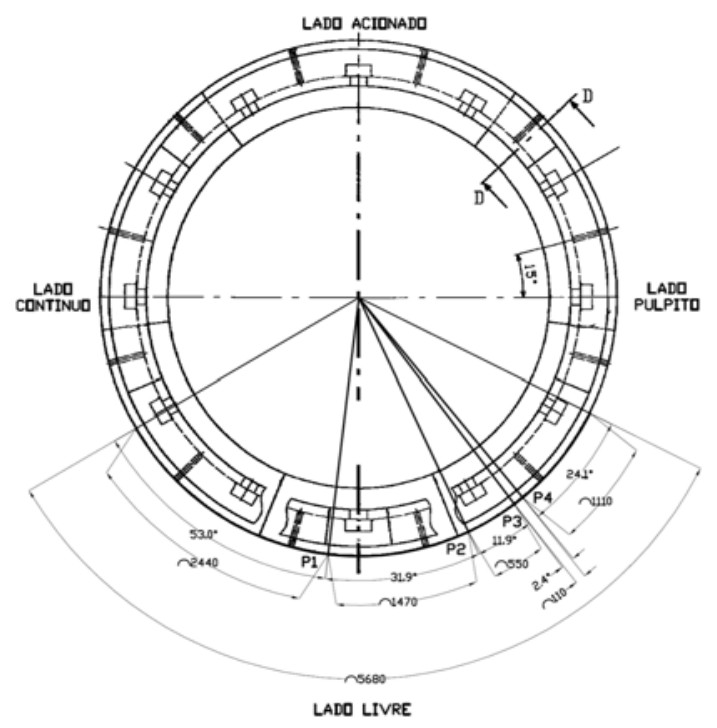

Figura 14. Disposição das nervuras do fundo com relação aos locais de iniciação da fratura.

Observando a disposição das nervuras do fundo com relação aos locais de iniciação da fratura não se verifica correlação, ver figura 14 . 


\subsection{Ensaios Mecânicos}

\subsubsection{Ensaio de tração}

Foram retiradas amostras da chapa do cone inferior, região substituída da carcaça para realização dos ensaios de tração na transversal e na longitudinal. $\mathrm{Na}$ especificação da chapa do cone inferior não há requisito no eixo $Z$, portanto não será realizado teste na espessura.

\subsubsection{Ensaio de tração na transversal}

Tabela 1. Ensaio de tração na transversal

\begin{tabular}{|c|c|c|c|c|}
\hline \multicolumn{5}{|c|}{ Ensaio de tração na transversal- CP cilíndrico } \\
\hline $\mathbf{N}^{\circ}$ do CP & LE Min 0.2\%( MPa) & LR (MPa) & AL\% Min & RA \% \\
\hline 1 & 350 & 484 & 34 & 62 \\
\hline 2 & 345 & 484 & 34 & 63 \\
\hline 3 & 340 & 482 & 35 & 63 \\
\hline $\begin{array}{c}\text { DIN EN 10028-2 } \\
\text { Gr 16Mo3 }\end{array}$ & 240 & $430-560$ & 22 & - \\
\hline
\end{tabular}

Os valores medidos no teste de tração realizado nos corpos de prova da transversal estão de acordo com o especificado na norma DIN EN 10028-2.

\subsubsection{Ensaio de tração na longitudinal}

Tabela 2. Ensaio de tração na longitudinal

\begin{tabular}{|c|c|c|c|c|}
\hline \multicolumn{5}{|c|}{ Ensaio de tração na longitudinal - CP cilíndrico } \\
\hline $\mathbf{N}^{\circ}$ do CP & LE Min 0.2\%( MPa) & LR(MPa) & AL\% min & RA \% \\
\hline 1 & 321 & 486 & 37 & 63 \\
\hline 2 & 333 & 486 & 37 & 62 \\
\hline 3 & 324 & 488 & 33 & 61 \\
\hline $\begin{array}{c}\text { DIN EN 10028-2 } \\
\text { Gr 16Mo3 }\end{array}$ & 240 & $430-560$ & & \\
\hline
\end{tabular}

Os valores medidos no ensaio de tração realizado nos corpos de prova da longitudinal estão de acordo com o especificado na norma DIN EN 10028-2.

\subsubsection{Ensaio de impacto Charpy $\mathrm{V}$}

Com o objetivo de se avaliar a tenacidade da chapa removida do cone inferior foram retidadas amostras para cortes de corpos de prova na longitudinal e na transversal para realização de teste de impacto charpy a $+20 \mathrm{C}$.

\subsubsection{Ensaio Charpy na Transversal}

Tabela 3. Resultados do ensaio de impacto charpy na direção transversal

\begin{tabular}{|c|c|c|c|}
\hline & Amostra 1 & Amostra 2 & Amostra 3 \\
\hline $\begin{array}{c}\text { Energia absorvida no } \\
\text { ensaio a }+20^{\circ} \mathrm{C}\end{array}$ & $31,2 \mathrm{~J}$ & $32,8 \mathrm{~J}$ & $47,5 \mathrm{~J}$ \\
\hline $\begin{array}{c}\text { DIN EN 10028-2 Gr 16Mo3 } \\
\left(+20^{\circ} \mathrm{C}\right)\end{array}$ & & $31 \mathrm{~J} \mathrm{~min}$ \\
\hline
\end{tabular}


Os resultados do teste de impacto atendem ao especificado na norma DIN EN 10028-2, e o aspecto da superfície tem aproximadamente $10 \%$ de fratura dúctil.

\subsubsection{Ensaio de Charpy na Longitudinal}

Tabela 4. Resultados do ensaio de impacto charpy na direção longitudinal

\begin{tabular}{|c|c|c|c|}
\hline & Amostra 1 & Amostra 2 & Amostra 3 \\
\hline $\begin{array}{c}\text { Energia absorvida } \\
\text { no teste } \mathrm{a}+20^{\circ} \mathrm{C}\end{array}$ & $81,4 \mathrm{~J}$ & $101,4 \mathrm{~J}$ & $62,4 \mathrm{~J}$ \\
\hline $\begin{array}{c}\text { DIN EN } 10028-2 \mathrm{Gr} \\
16 \mathrm{Mo3}\left(+20^{\circ} \mathrm{C}\right)\end{array}$ & \multicolumn{3}{|c}{ 31J min } \\
\hline
\end{tabular}

Os resultados do teste de impacto atendem ao especificado na norma DIN EN $10028-2$, e o aspecto da superfície tem aproximadamente $10 \%$ de fratura dúctil.

\subsection{Análise Química}

De acordo com a análise feita no laboratório químico da Aciaria têm-se a seguinte composição para a chapa do convertedor:

Tabela 5. Composição química da chapa (\%)

\begin{tabular}{|c|c|c|c|c|c|c|c|c|c|}
\hline Elemento & $\mathbf{C}$ & $\mathbf{S i}$ & $\mathbf{M n}$ & $\mathbf{P}$ & $\mathbf{S}$ & $\mathbf{C r}$ & $\mathbf{C u}$ & $\mathbf{M o}$ & $\mathbf{N i}$ \\
\hline Amostra & 0,19 & 0,24 & 0,77 & 0,022 & 0,0031 & 0,046 & 0,043 & 0,29 & 0,040 \\
\hline DIN EN 10028-2 & $0,12-$ & $\leq 0,35$ & $0,4-$ & $0,025-$ & $0,010-$ & $\leq 0,30$ & $\leq 0,30$ & $0,25-$ & $\leq 0,30$ \\
Gr 16Mo3 & 0,20 & & 0,9 & máx & máx & & & 0,35 & \\
\hline
\end{tabular}

A composição química encontrada no ensaio de laboratório da Aciaria está de acordo com a especificação do material especificado DIN EN 10028-2 Gr 16Mo3.

\subsection{Análise Metalográfica}

Foi realizada micrografia ao longo da espessura da chapa do costado $(75,0 \mathrm{~mm})$, a amostra foi retirada próxima à trinca e na direção longitudinal da chapa, o objetivo foi verificar a condição microestrutural devido a exposição à alta temperatura, ver figuras 15 a 22 .

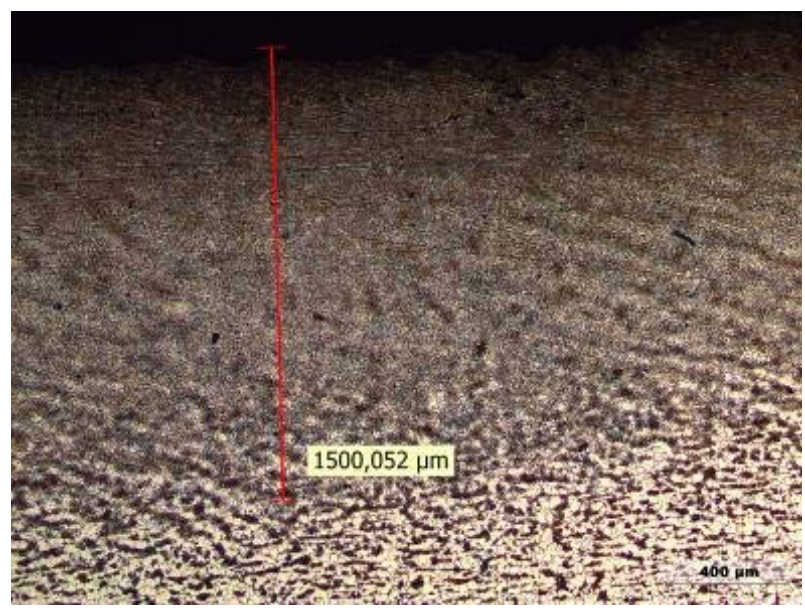

Figura 15. Degradação na face interna com profundidade de $1,5 \mathrm{~mm}(50 \mathrm{X})$.

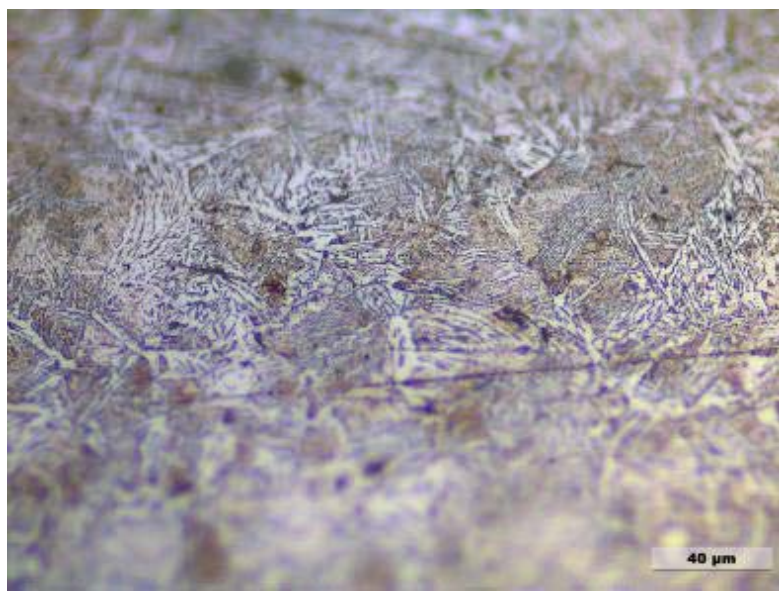

Figura 16. Região degradada de $1,5 \mathrm{~mm}$, grãos colunares característico de sobreaquecimento (1000X). 


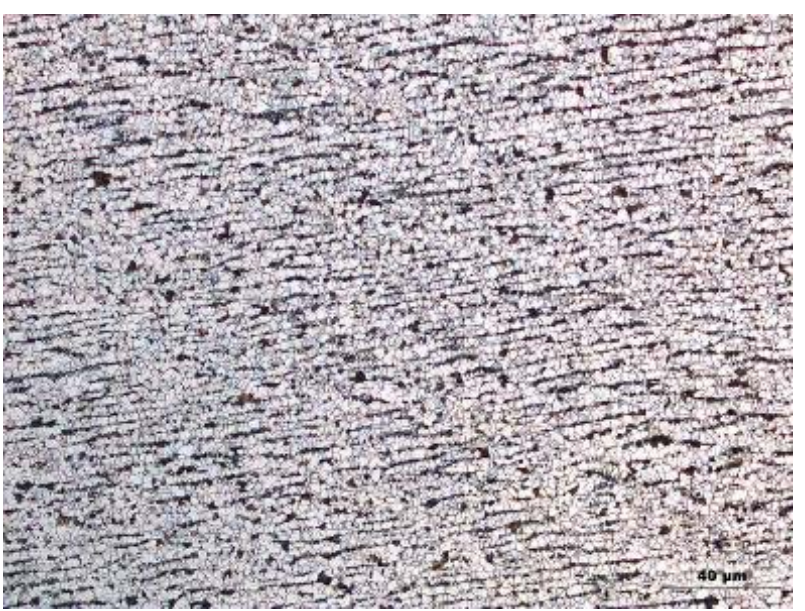

Figura 17. Região interna (1/4 a partir da superfície interna), microestrutura característica de material laminado (50X).

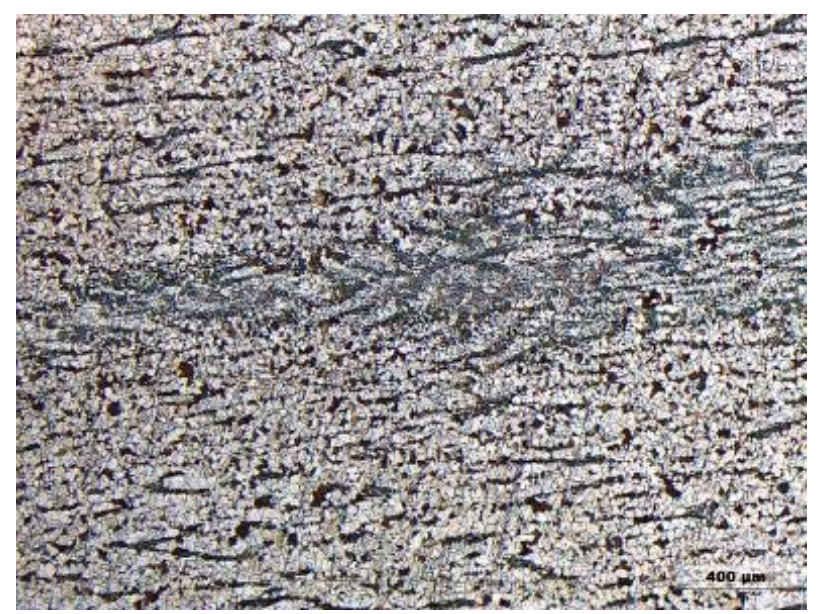

Figura 19. Região central ( $1 / 2$ espessura), presença de segregação central típica de chapa grossa, concentração perlita e sulfetos (50x).

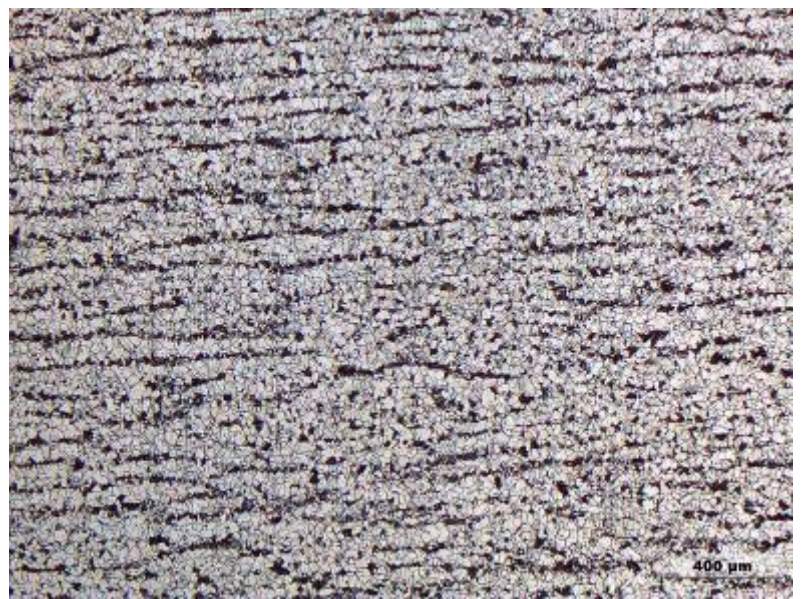

Figura 21. Região externa (3/4 a partir da superfície interna), grãos alongados característica da laminação (50X).

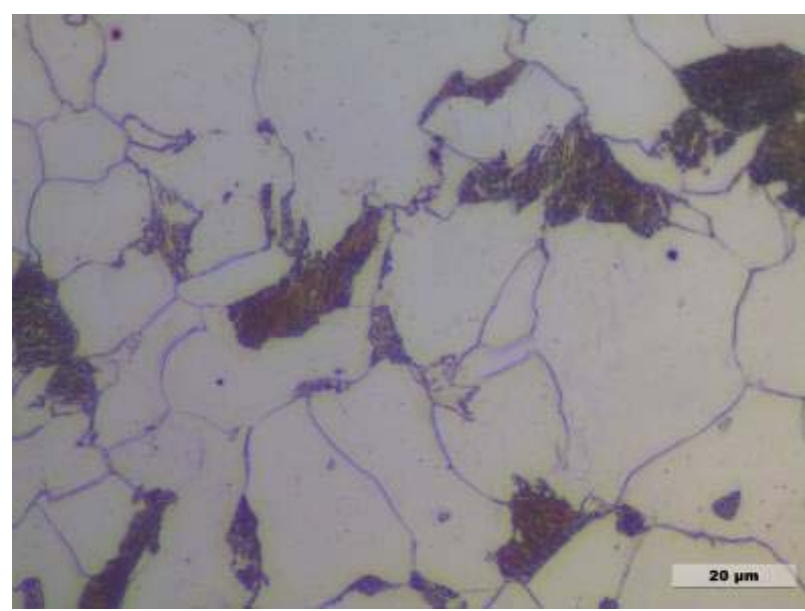

Figura 18. Região interna (1/4 a partir da superfície interna), microestrutura em fase inicial de degradação (1000X).

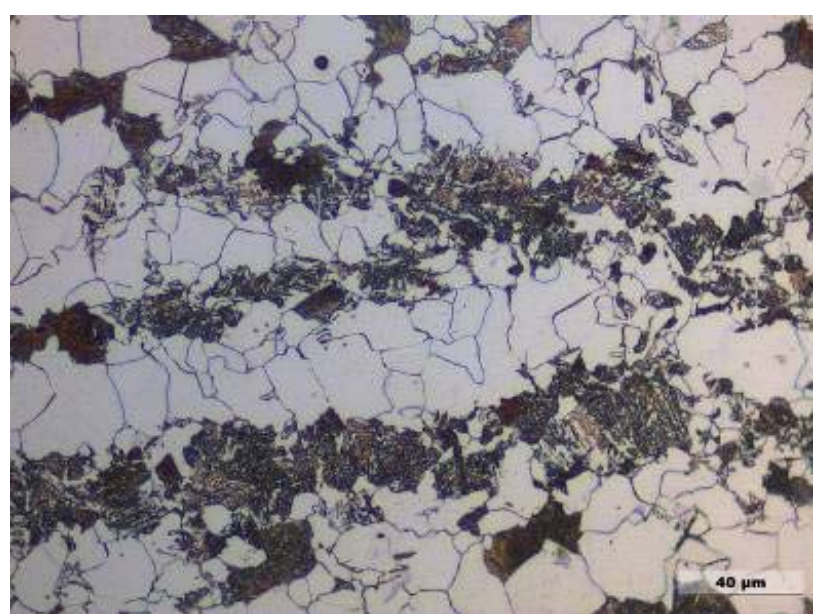

Figura 20. Região central (1/2 espessura), microestrutura íntegra, presença de veios de perlita e sulfetos (500X).

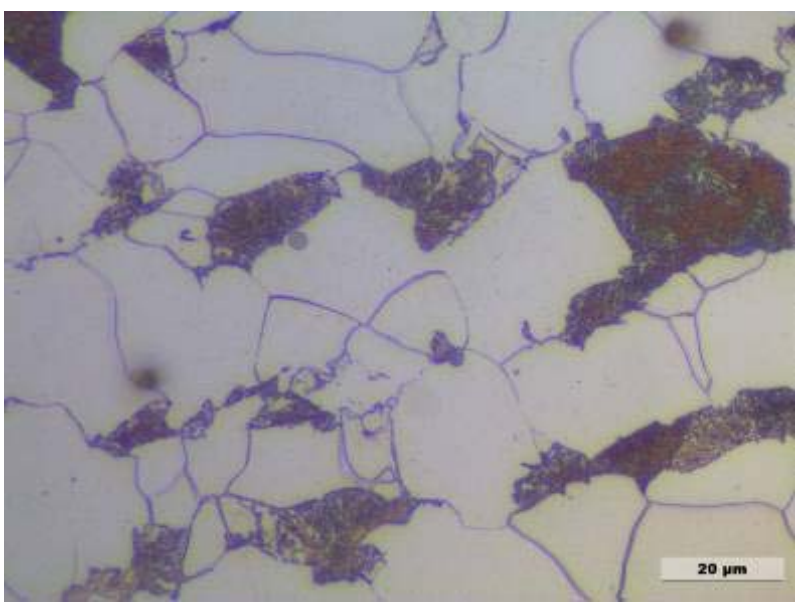

Figura 22. Região externa (3/4 a partir da superfície interna), microestrutura preservada com a perlita íntegra (1000X). 
A microestrutura da chapa apresenta-se na condição esperada, sem degradação significativa, exceto na face interna onde se verifica na profundidade de $1,5 \mathrm{~mm}$, degradação pela exposição à alta temperatura do refratário. Não há diferença significativa na condição microestrutural ao longo da espessura.

\subsection{Projeto de refratário - Fornecedor}

Foi construído o modelo 3D em CAD do convertedor, uma vez que o mesmo não apresenta axissimetria, todos os detalhamentos pertinentes à uma análise termo estrutural foram incluídos no modelo. As propriedades térmicas dos materiais refratários foram consideradas variando com a temperatura pois a faixa de temperatura de trabalho é considerável. Na figura 24, são mostradas algumas das propriedades térmicas do refratário que foram incluídas no modelo matemático para simulação numérica.

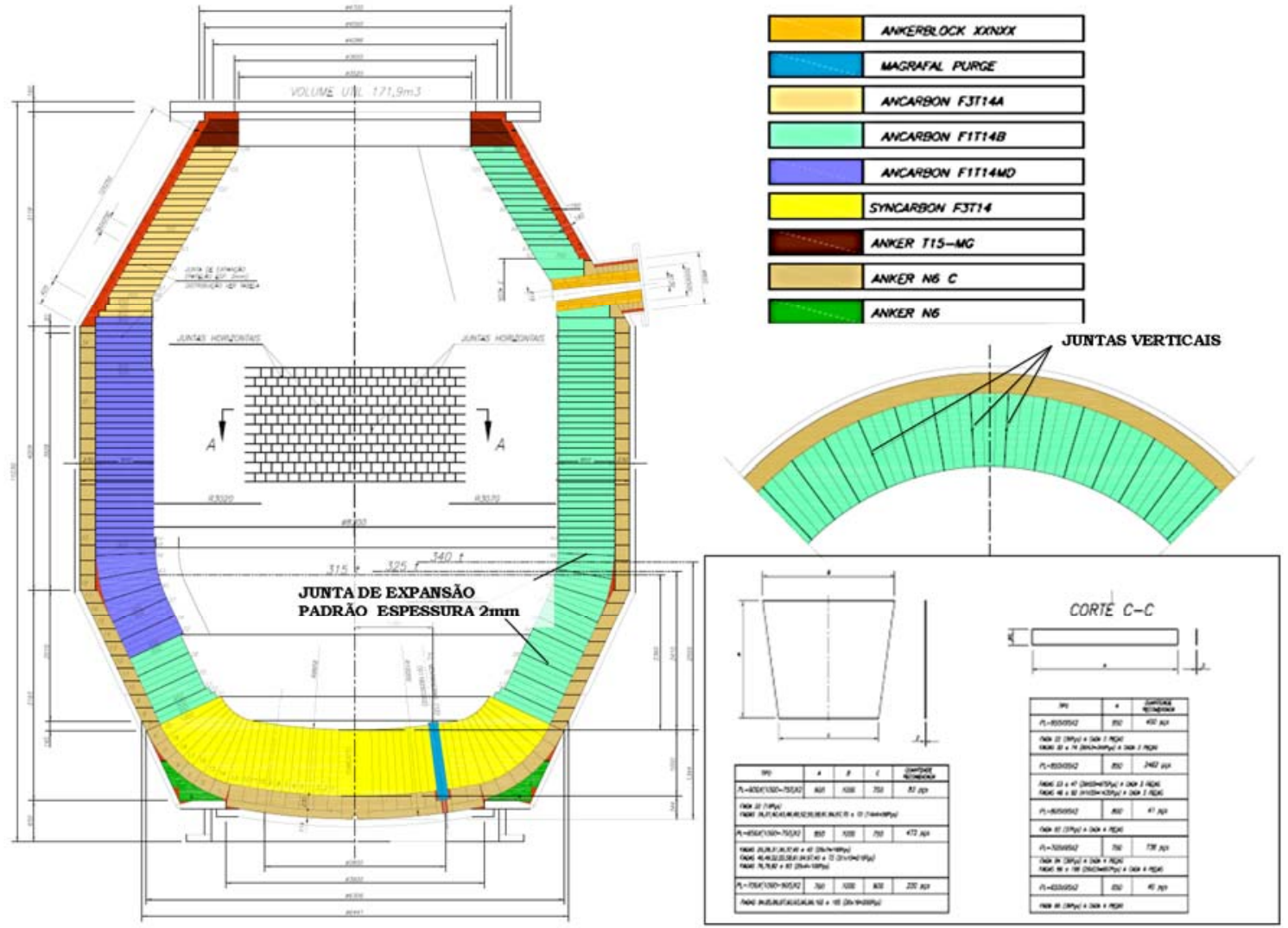

Figura 23. Projeto de refratário do fornecedor.

\subsubsection{Propriedades do refratário}

$\mathrm{Na}$ construção do modelo de análise, a disposição do material refratário no convertedor seguiu o projeto de refratário do fornecedor, conforme o desenho apresentado na figura 23.

Neste projeto, a especificação de juntas de dilatação (papelão) depende da direção e região do convertedor a ser montada, isto é, os números de juntas podem variar se compararmos o cone superior, corpo cilíndrico e cone inferior e a instalação das mesmas estão relacionada ao número de fiadas de tijolos. Na região do fundo do convertedor não é previsto a instalação de junta de dilatação.

Todos os dados relativos a propriedades térmicas e mecânicas dos refratários foram fornecidos pelo fornecedor, ver figura 24. 
Na figura 25, é apresentado o modelo geométrico com a disposição de todos os refratários conforme o projeto do fornecedor.

- Condutividade térmica x Temperatura

- Coeficiente de expansão x Temperatura

\begin{tabular}{|c|c|c|}
\hline Temperature $\left({ }^{\circ} \mathrm{C}\right)$ & Thermal Expansion (\%) & Thermal Conductivity $(\mathrm{W} / \mathrm{m} . \mathrm{T})$ \\
\hline $\mathbf{5 0 0}$ & 0,4 & 14 \\
\hline 750 & 0,7 & 11,5 \\
\hline 1000 & 0,95 & 10 \\
\hline 1200 & 1,3 & 9 \\
\hline 1400 & 1,6 & 8,5 \\
\hline
\end{tabular}

\begin{tabular}{|c|}
\hline ANAERESOCX XCNOX \\
\hline MUGNAFN PUREE \\
\hline ACAPQON FJTIM \\
\hline NCARean FITIAB \\
\hline NCrPBaN FITHAWD \\
\hline SnCAPBON FITI \\
\hline MNERR IIS-MG \\
\hline ANKES NE C \\
\hline ANKER N6 \\
\hline
\end{tabular}
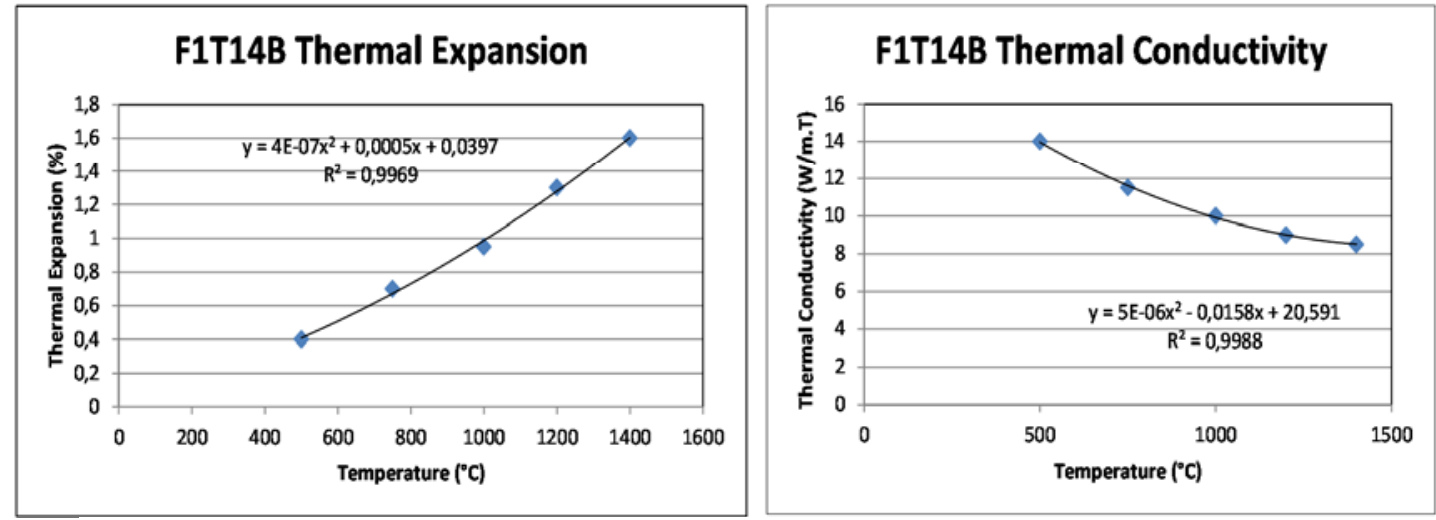

Figura 24. Propriedades do refratário x Temperatura.

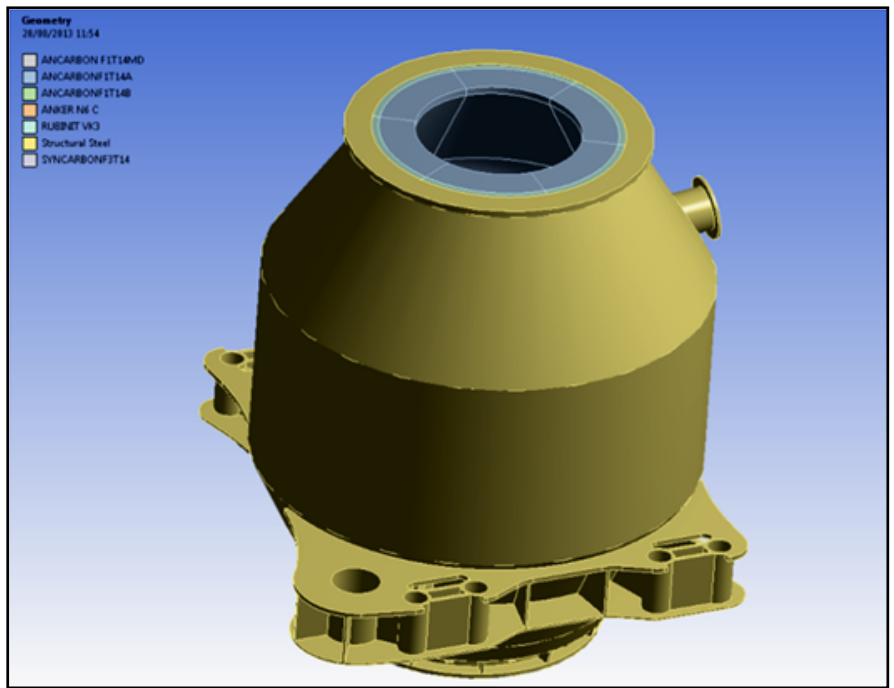

Figura 25. Modelo Geométrico.

\subsubsection{Condição de contorno}

Para a térmica foram consideradas as seguintes condição de contorno:

- Temperatura interna $-1650{ }^{\circ} \mathrm{C}$;

- Convecção - condição ambiente com pouco vento - Coeficiente de pelicula de $15 \mathrm{~W} / \mathrm{m}^{2}{ }^{\circ} \mathrm{C}$;

- Radiação - emissividade de 0,9 e temperatura ambiente de $35^{\circ} \mathrm{C}$. 


\subsubsection{Resultado de temperatura}

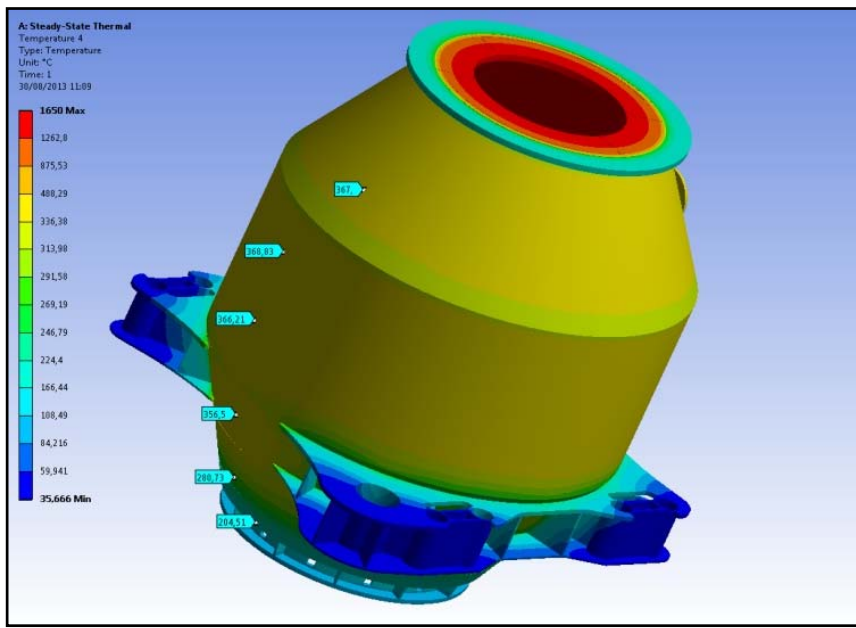

Figura 26. Resultado de Temperatura.

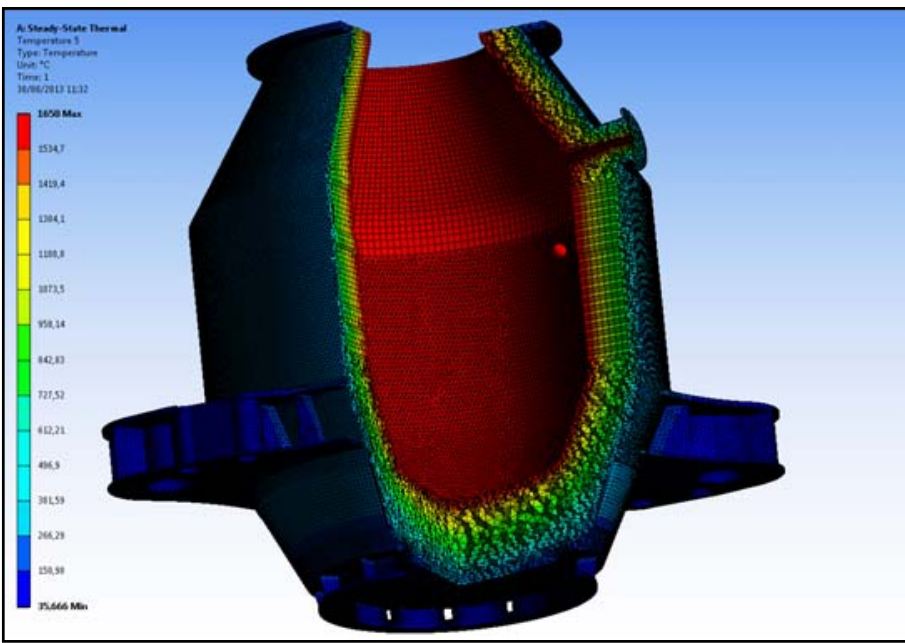

Figura 28. Resultado de Temperatura.

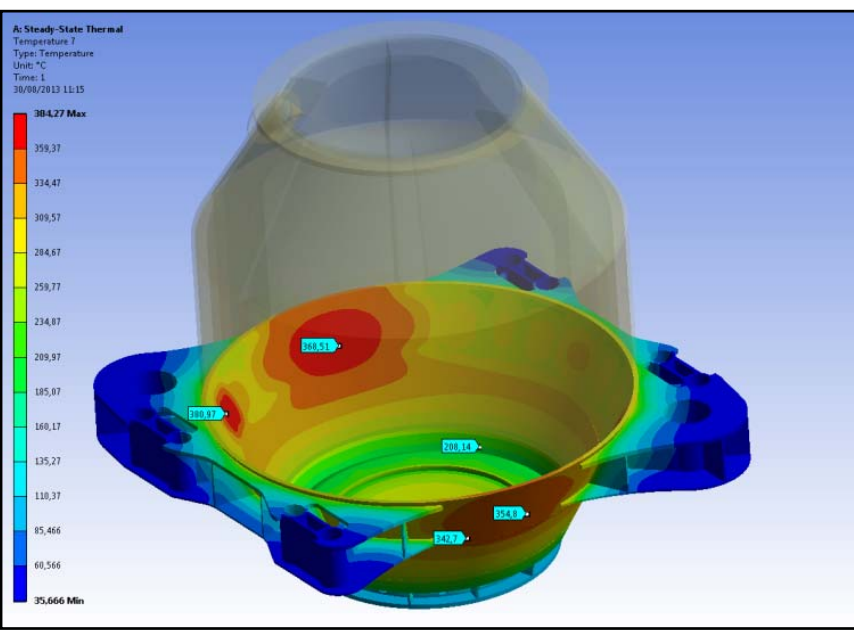

Figura 27. Resultado de Temperatura - Costado Interno.

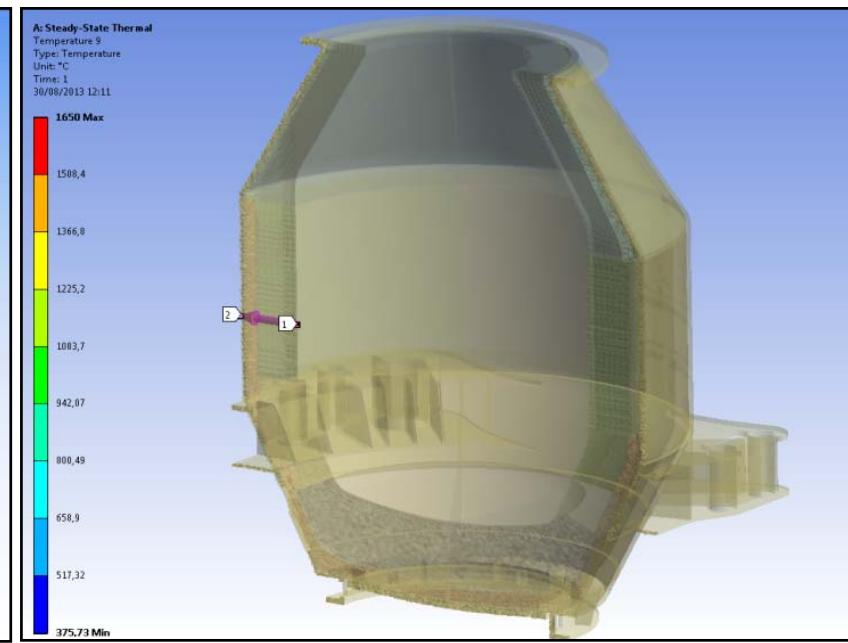

Figura 29. Resultado de Temperatura Caminho $1-2$.

Os resultados das figuras 26 a 28 mostram o perfil de temperatura ao longo da carcaça do convertedor e no refratário. Os mesmos foram comparados com os valores obtidos por termografia, foram observadas poucas variações entre os mesmos.

$\mathrm{Na}$ figura 29, é apresentado o resultado da variação radial de temperatura ao longo do caminho 1-2, e na figura 30 o resultado do fornecedor também ao longo do caminho 1-2. Pode-se observar que os resultados apresentam um comportamento bem similar. 

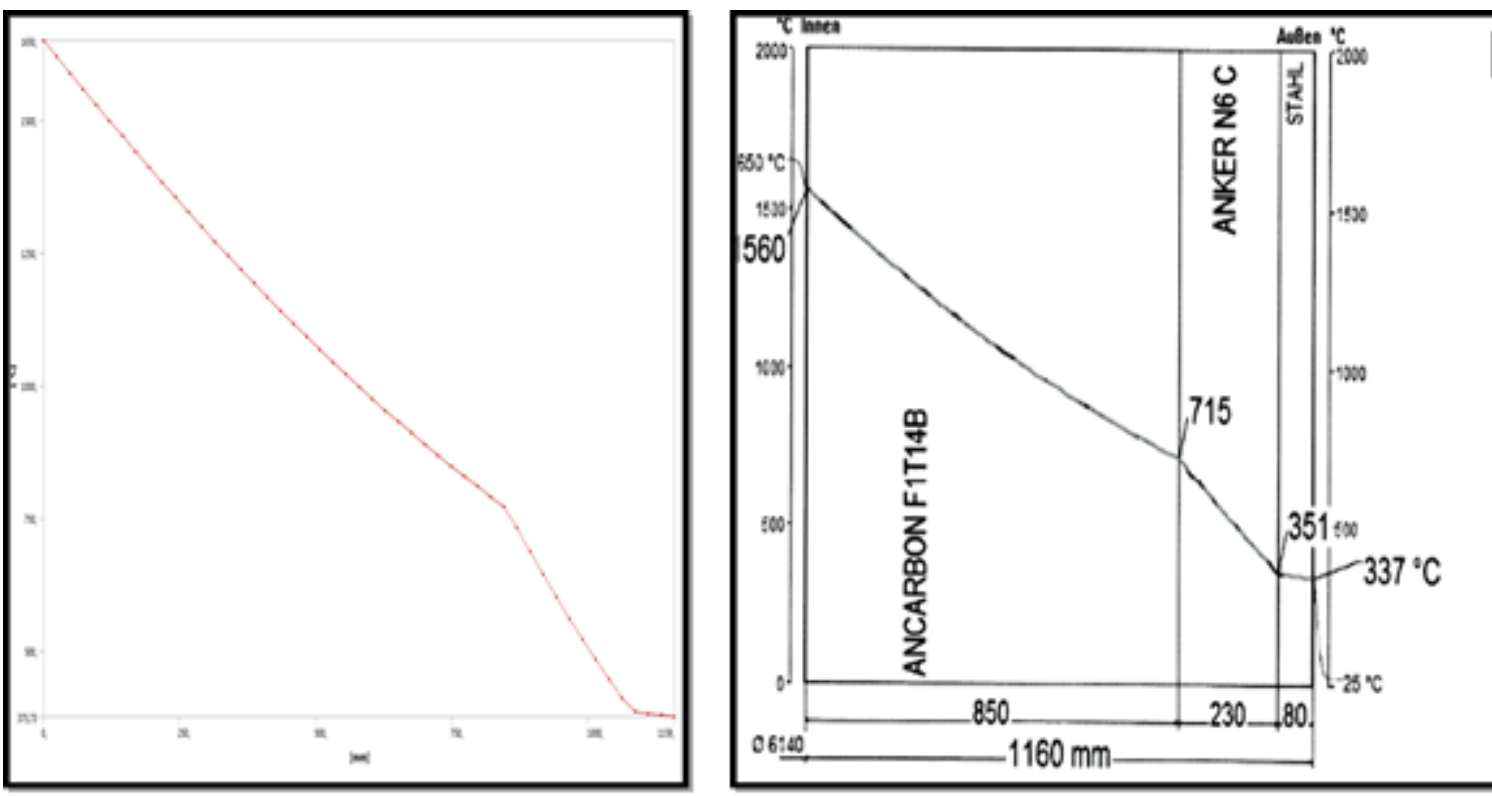

Figura 30. Resultado de Temperatura do fornecedor - Caminho $1-2$

\subsubsection{Condição de contorno - análise termo estrutural - contato}

Obtidos os resultados da análise térmica, deve-se realizar a análise estrutural acoplada para determinar os níveis de tensões que o costado fica submetido para as diversas condições de carga a serem analisadas. Visando minimizar o esforço computacional da análise estrutural, o convertedor foi subdividido em seis seções no sentido radial e três no sentido longitudinal, onde na interface das seções foram utilizados elementos de contato para representar a totalidade dos gaps (juntas de dilatação) compreendidos entre a interface de contato das seções, ver figura 31 e tabela 6.

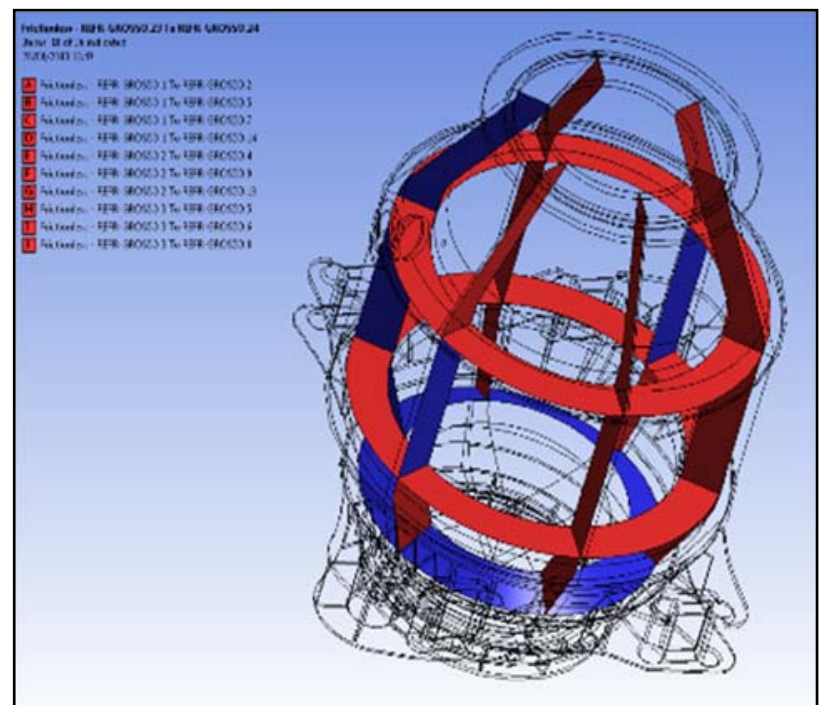

Figura 31. Interface das seções.

Tabela 6. Junta de dilatação

\begin{tabular}{|c|c|c|}
\hline \multicolumn{3}{|c|}{ JUNTA DE DILATAÇÃO } \\
\hline & Horizontal & Vertical \\
\hline Cone superior & $-18 \mathrm{~mm}$ & $-9,66 \mathrm{~mm}$ \\
\hline Cilindro & $-20 \mathrm{~mm}$ & $-16 \mathrm{~mm}$ \\
\hline Cone inferior & $-14 \mathrm{~mm}$ & $-13,8 \mathrm{~mm}$ \\
\hline
\end{tabular}




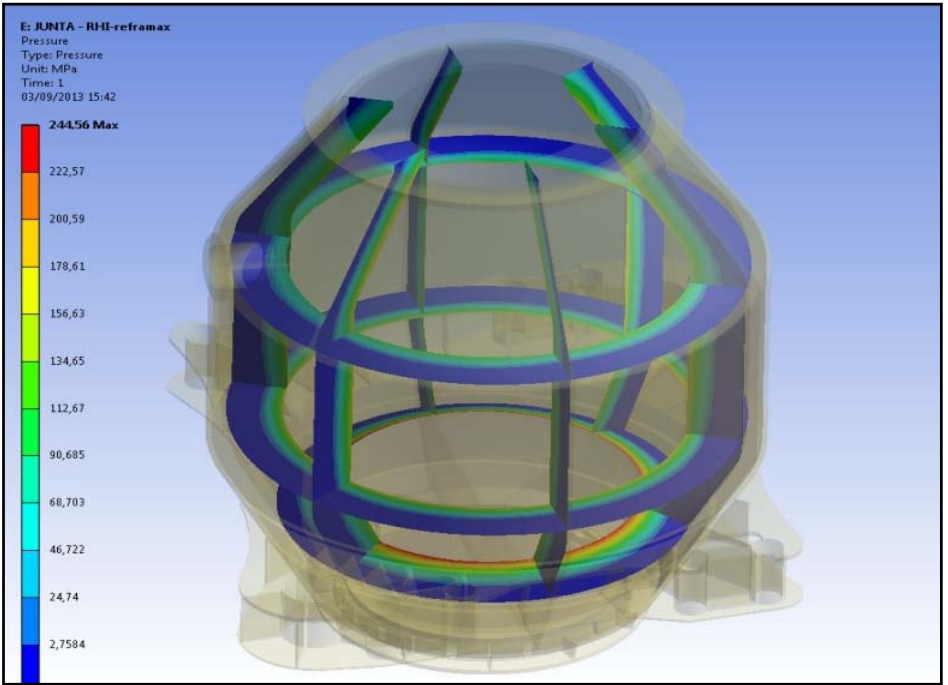

Figura 32. Elemento de contato - Pressão.

\subsubsection{Resultado de Tensões}

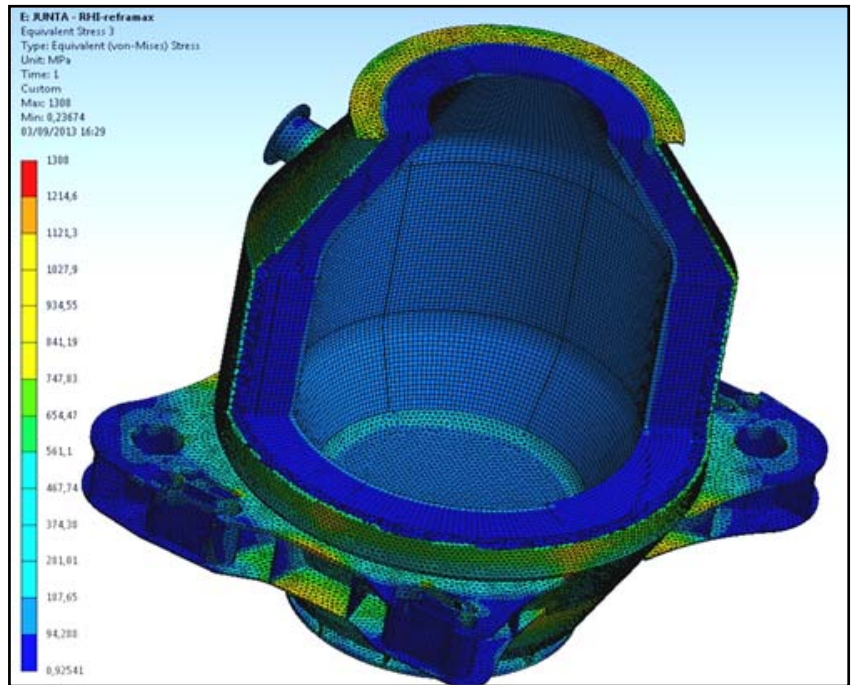

Figura 33. Tensões de von Mises.

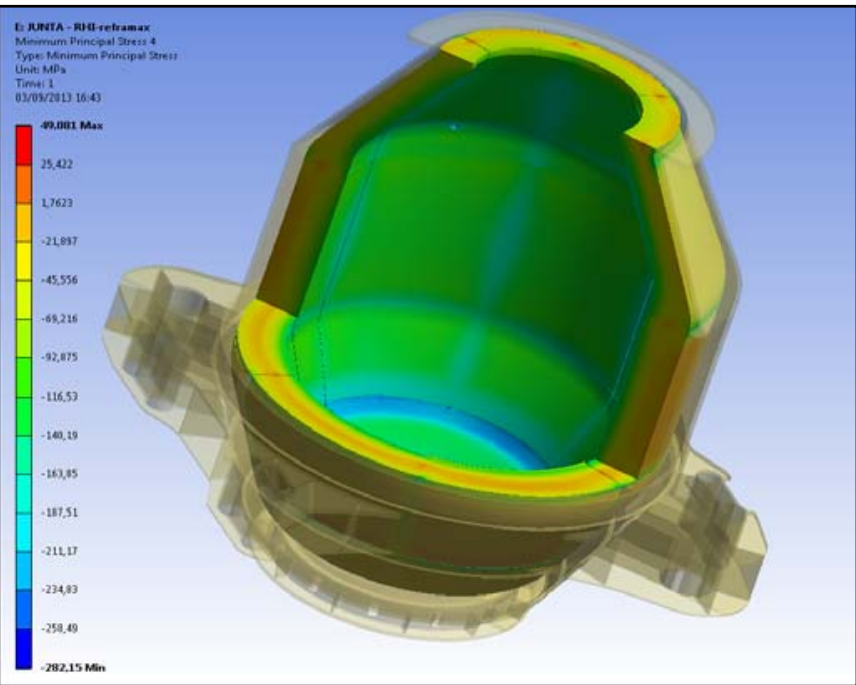

Figura 34. Tensão Principal S3 - Refratário.

\subsubsection{Perfil de Refratário - Metrix - Soleira}
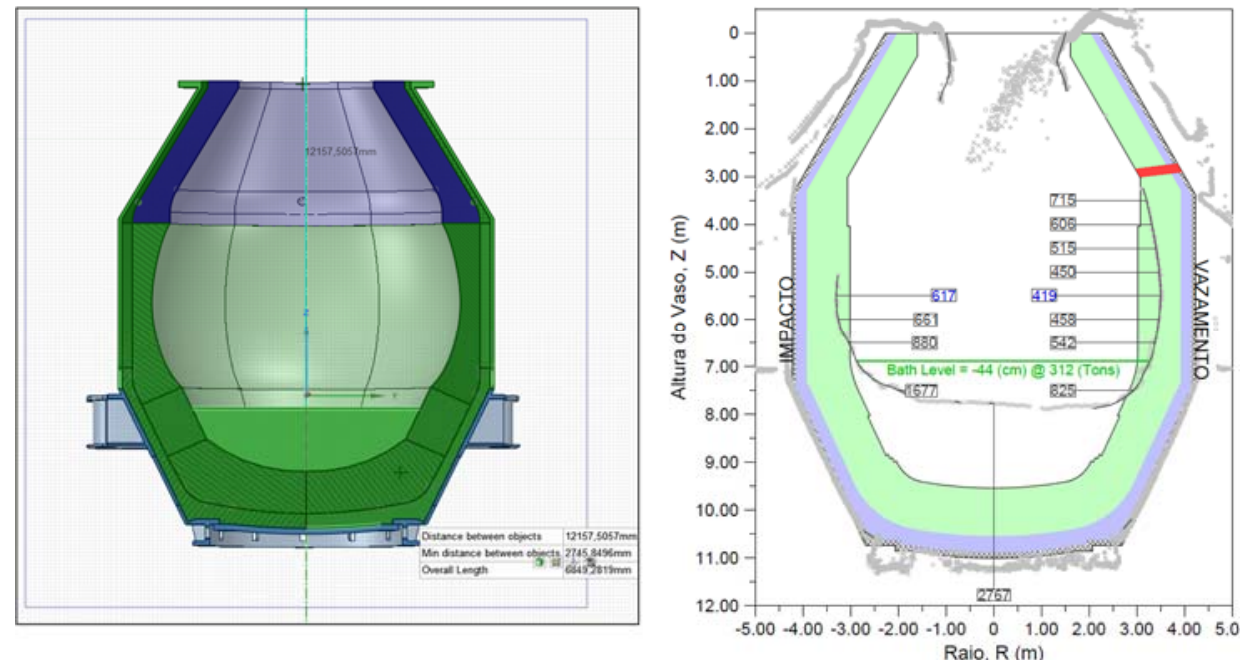

Figura 35. Perfil de desgaste de Refratário com Soleira. 


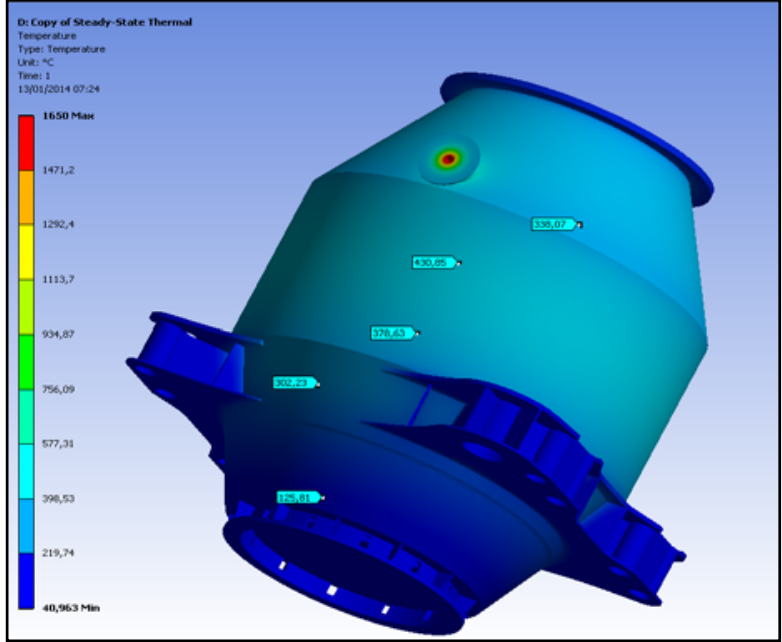

Figura 36. Temperatura no costado com Desgaste/ Soleira.

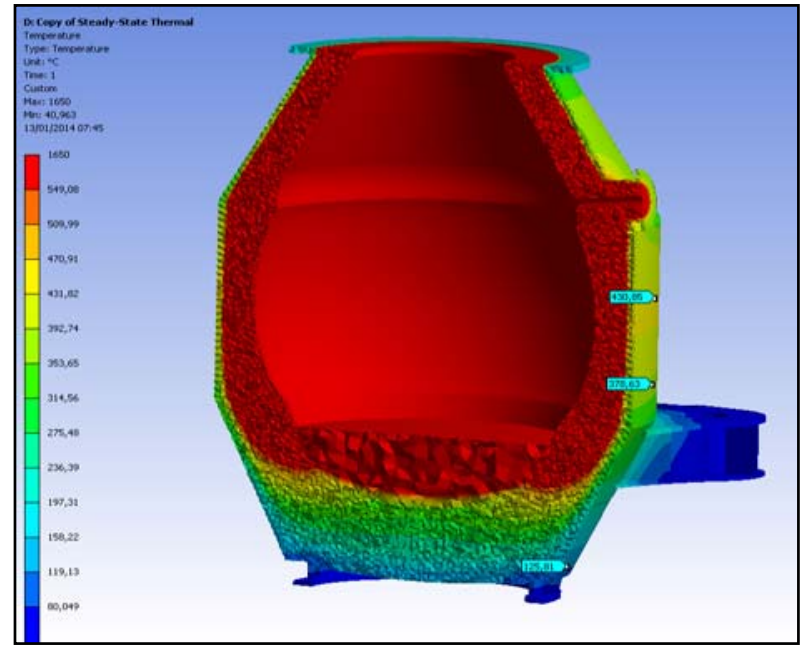

Figura 37. Temperatura - Seção do Convertedor com Desgaste/ Soleira.

\subsubsection{Resultado de Tensões}

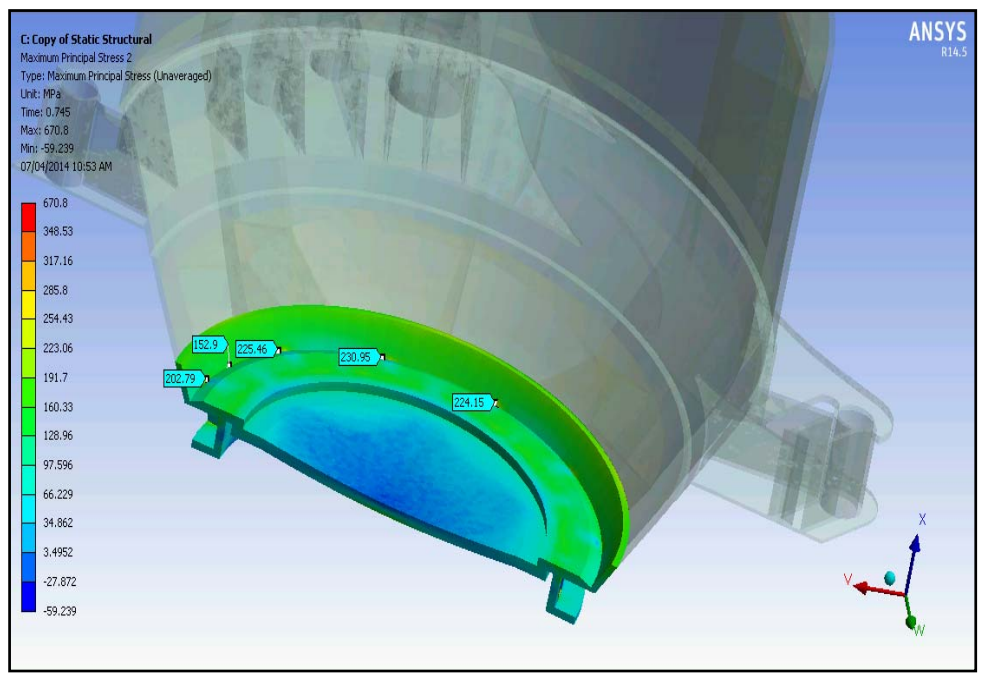

Figura 38. Tensão S1 - Fundo do Convertedor - Soleira.

\section{RESULTADOS E DISCUSSÃO}

- Condições analisadas:

- Projeto do fornecedor do refratário - junta de papelão;

- Projeto com Junta natural 0,2 mm;

- Carregamento térmico;

- Projeto com soleira;

- A distribuição da temperatura ao longo da espessura é similar ao apresentado pelo estudo do fornecedor;

- As tensões térmicas oriundas apenas das variações de temperatura do costado estão dentro do admissível;

- Todos os contatos foram fechados, ou seja, as juntas de dilatação estão trabalhando;

- A temperatura máxima no costado está dentro do admissível;

- Material do costado do convertedor atende a especificação da DIN EN 10028-2 Gr 16 Mo3. 


\section{CONCLUSÃO}

- A trinca ocorrida no costado do vaso, mais especificamente na ZTA da solda do cone inferior e o anel do fundo do convertedor 2 não foi decorrente de imperfeição de solda, de propriedades mecânicas, de composição química ou de degradação microestrutural do material do vaso.

- A superfície de fratura apresenta 4 pontos de origem da trinca, sem sítios de fadiga, ou concentradores de tensão da solda original, a fratura propagou-se desses pontos da superfície interna do vaso para a superfície externa de maneira instantânea.

- A deformação plástica na chapa do cone inferior na região da fratura sugere que houve um esforço radial no sentido de abertura do cone inferior na região de falha, portanto deve-se verificar a condição de dilatação entre o refratário e o costado.

- De acordo com as análises realizadas, a causa da falha do convertedor esta relacionada a esforços oriundos da expansão térmica do refratário;

- Considerando apenas a contribuição das juntas de dilatação de papelão o valor da tensão máxima atuante está acima da tensão admissível do costado do convertedor.

- As tensões atuantes no costado quando considerado um valor da folga natural de $0,2 \mathrm{~mm}$, conforme informação do fornecedor, estão abaixo da tensão admissível, apresentando neste caso um fator de segurança de 0,5 .

- É importante o controle das propriedades do refratário no fornecimento, assim como o controle das juntas de dilatação na montagem.

\section{BIBLIOGRAFIA}

AISE 9 - Specifications for Design of Ladles.

2 ANSYS 15.0 - Software de análise por elementos finitos.

3 DIN EN 10028-2 (2003-09) "Flat products made of steels for pressure purposes - Part 2: Non-alloy and alloy steels with specified elevated temperature properties". 